\title{
ATIVIDADES DESENVOLVIDAS PELO PROJETO DE EXTENSÃO DOENÇAS SEXUALMENTE TRANSMISSÍVEIS E HEPATITES VIRAIS
}

Marcela FORGERINI ${ }^{1}$

Gustavo Bruno GONÇALVES ${ }^{2}$

Sandra Maria Oliveira Morais VEIGA ${ }^{3}$

\begin{abstract}
${ }^{1}$ Graduada em Farmácia pela Universidade Federal de Alfenas (UNIFAL). marcelinha_forgerini @ hotmail.com
${ }^{2}$ Graduando em Medicina pela Universidade Federal de Alfenas (UNIFAL). gustavobruno1992@hotmail.com.

${ }^{3}$ Doutora, Professora da Universidade Federal de Alfenas (UNIFAL). smveiga@gmail.com
\end{abstract}

Recebido em: 11/04/2016 - Aprovado em: 14/10/2016 - Disponibilizado em: 18/12/2016

\begin{abstract}
RESUMO:
Este trabalho apresenta as atividades realizadas e os resultados obtidos pelo projeto de extensão Doenças Sexualmente Transmissíveis (DST) e Hepatites Virais, da Universidade Federal de Alfenas (UNIFAL-MG), nos anos de 2013 , 2014 e 2015. Objetivou-se difundir informações sobre DST, Síndrome da Imunodeficiência Adquirida (AIDS), Hepatites Virais e Sexualidade, capacitando jovens e adultos para a prevenção, diagnóstico precoce e tratamento oportuno dessas doenças. Ainda, formar multiplicadores do conhecimento e minimizar o preconceito. A metodologia do projeto é interativa, estimulando a troca de conhecimentos e saberes entre a população e a comunidade acadêmica. Para tanto, foram organizadas palestras, oficinas e eventos com montagem de stands educativos. Ainda, foram criadas e disponibilizadas ferramentas online - BLOG (http://dstaidsunifal.blogspot.com.br/) e página no facebook (https://www.facebook.com/dstaidsunifal). O projeto foi desenvolvido em escolas dos ensinos fundamental e médio, no cursinho pré-vestibular, na UNIFAL-MG, no CVT (Centro Vocacional Tecnológico), na UNATI (Universidade Aberta a Terceira Idade), no CRAS (Centro de Referência de Assistência Social de Alfenas) e na Associação Beneficente CARITAS.Ainda, foram organizadas campanhas educativas para a população local. Nas escolas de diferentes níveis, foi feito um levantamento de dados sobre o conhecimento em relação ao tema, concluindo que, apesar da alta exploração pela mídia, ainda existem muitas dúvidas. Estes achados apontam uma situação preocupante, que demanda esforços para atividades educativas continuadas.
\end{abstract}

Palavras-chave: Sexualidade. Doenças Sexualmente Transmissíveis. Hepatite. Síndrome de Imunodeficiência Adquirida. Prevenção.

\begin{abstract}
:
This work presents the activities carried out and the results of the extension project Sexually Transmitted Diseases (STD) and Viral Hepatitis of the Federal University of Alfenas (UNIFAL-MG) in the years 2013, 2014 and 2015. The objective was to disseminate information on STD, Acquired Immune Deficiency Syndrome (AIDS), Hepatitis and Sexuality, empowering young people and adults for the prevention, early diagnosis and timely treatment of these diseases. Also form multipliers of knowledge and minimize bias. The project methodology is interactive, stimulating the exchange of knowledge and expertise between the public and the academic community. To this end, talks were held, workshops and events for educational assembly of stands. Yet, they were created and made available online tools BLOG (http://dstaidsunifal.blogspot.com.br/) and Facebook page (https://www.facebook.com/dstaidsunifal). The project was developed in schools of primary and secondary education in the pre-university preparatory course in UNIFAL-MG, CVT (Vocational Technology Center) and UNATI (Open University to the Elderly). Yet, educational campaigns for the local population were organized. In schools of different levels, it was made a data survey of knowledge regarding the subject, concluding that, despite the high exploitation by the media, there are still many doubts. These findings point to a worrying situation, which requires continued efforts to educational activities.

Keywords: Sexuality. Sexually Transmitted Diaseases. Hepatitis. Acquired Immunodeficiency Syndrome. Prevention.
\end{abstract}




\section{INTRODUÇÃO}

Segundo a Organização Mundial de Saúde (OMS), as Doenças Sexualmente Transmissíveis - DST são transmitidas por qualquer tipo de contato sexual, sem o uso de preservativo. Geralmente, elas se manifestam por meio de feridas, corrimentos, bolhas, verrugas e algumas dessas doenças podem levar a sintomas sistêmicos.

As mais conhecidas são gonorreia e a sífilis, representando um grande desafio para as autoridades de saúde e educação do mundo atual, prevalecendo entre os jovens, que em sua maioria tem iniciado a vida sexual, cada vez mais cedo, na faixa etária de 12 a 17 anos.Entretanto, estão presentes em todos os grupos etários e sociais (BRASIL, 2015).

A OMS estima que ocorram mais de 340 milhões de novos casos de DST curáveis (bacterianas e protozoárias) anualmente, no mundo, acometendo homens e mulheres entre 15 e 49 anos de idade, sendo quase $80 \%$ desses casos nos países em desenvolvimento (WHO, 2001; WHO, 2007). No Brasil, a incidência anual estimada das DST é de 10 a 12 milhões de casos (BRASÍLIA, 2008)

De acordo com o Boletim Epidemiológico AIDS e DST (2014), a taxa de detecção de AIDS, entre o público com mais de 60 anos por 100 mil habitantes, cresceu mais de $80 \%$ nos últimos 12 anos no país, sendo uma realidade preocupante (BRASIL, 2014).Embora esse aumento seja evidente, esses indivíduos ainda possuem poucas informações a respeito dos aspectos relacionados a tratamento, infecção e prevenção. $\mathrm{O}$ que provavelmente contribui para o reduzido investimento em estratégias de prevenção nesta faixa etária da população. (PEREIRA, 2010).

Quando não diagnosticadas e tratadas oportunamente, as DST podem evoluir para complicações, causando esterilidade, doença inflamatória pélvica, câncer de colo uterino, gravidez ectópica, infecções puerperais e recém-nascidos com baixo peso, além de interferir negativamente sobre a auto-estima. Algumas delas podem levar ao óbito (BELÉM, 1999).Segundo a OMS, as complicações das DSTs correspondem por aproximadamente $17 \%$ das perdas econômicas relacionadas com o binômio saúde / doença, representando uma das dez principais causas de procura a servições de saúde em países em deselvolvimento (MAYAUD, 2004).

Os jovens têm iniciado a vida sexual, cada vez mais cedo e eles não detem o conhecimento nem a maturidade para enfretarem os riscos que estão se expondo. Alguns deles não reconhecem o sexo anal e oral como fontes de contágio.E o preservativo, que poderiaevitar estas doenças é deixado de lado, muitas vezes por falta de informação, não gostar de usar, confiar no parceiro e pelo imprevisto em que as relações sexuais acontecem (BRASIL, 2015). Outros fatores como: falta de recursos para obtenção 
dos preservativos, influência do parceiro e uso de contraceptivo hormonal, também podem influenciar para a ocorrencia de relações sexuais desprotegidas (GIL, 2000).

Além da resistência ao uso de preservativos e a falta de conhecimento, os adolescentes apresentam outros comportamentos de risco para as DST: múltiplos parceiros sexuais, uso de álcool e drogas ilícitas e início sexual precoce. Alguns jovens ainda apresentam outras situações relacionas com a vulnerabilidade social, como baixa escolaridade, violência, falta de acesso amplo aos serviços de saúde e desemprego. (HOYOS, 2001).

“ Os jovens heterossexuais ainda não acreditam que é possível engravidar numa primeira relação. Já os homossexuais não acreditam que numa primeira relação seja possível se contaminar com doenças sexualmente transmissíveis. Além disso, como o HIV demora para se manifestar e nem sempre os sintomas são perceptíveis, a pessoa pensa que não se contaminou. $O$ 'nem sempre' usar preservativos poder ser fatal, pois basta uma única relação sem proteção para se contaminar", diz a médicaAlbertina Duarte Takiuti, do Programa Estadual de Saúde do Adolescente (TAKIUTI, A. D).

Assim, este projeto tem a finalidade de difundir informações sobre DST, AIDS e Hepatites Virais, capacitando jovens e adultos para a prevenção, diagnóstico precoce e tratamento oportuno dessas doenças. Ainda, formar multiplicadores do conhecimento, minimizar o preconceito e levantar dados que possam subsidiar ações futuras do referido projeto.

\section{OBJETIVO}

\section{MATERIAS E MÉTODOS:}

\subsection{MATERIAIS}

Álbum seriado de DST/AIDS, folders educativos, cartazes, materiais didáticos sobre órgãos genitais (pênis, vagina, aparelho reprodutor), preservativos (masculino $\mathrm{e}$ feminino), recursos audiovisuais (slides, filmes, vídeos) e instrumentos para levantamento do conhecimento e de avaliação das atividades (questionários simplificados).

\subsection{MÉTODOS}

A metodologia do projeto é interativa, estimulando a troca de conhecimentos e saberes entre a população e a comunidade acadêmica.

Para tanto, são organizadas palestras, oficinas e eventos com montagem de Stand's 
educativos. Ainda, são disponibilizadas ferramentas online - BLOG (http://dstaidsunifal.blogspot.com.br/) e $\begin{array}{lll}\text { página no facebook } & \end{array}$ (https://www.facebook.com/dstaidsunifal).

Em escolas e demais instituições de educação e saúde realizam-se palestras com a apresentação de slides/ vídeos/ DVD ou oficinas educativas com discussão em grupo sobre o assunto. Em ambas situações, o tema é debatido havendo o esclarecimento de dúvidas.

Empregam-se técnicas pedagógicas expositivas (palestras) ou interativas (oficinas, grupos de discussão / dinâmica de grupo), conforme tempo disponibilizado pela instituição parceira.

São multiplicadas informações sobre aparelho reprodutor masculino e feminino, reprodução, sexualidade responsável, Doenças Sexualmente Transmissíveis, incluindo a AIDS. Os assuntos são abordados de uma maneira clara, englobando: principais sinais e sintomas, formas de transmissão (sexual, sanguínea e congênita), complicações destas doenças, diagnóstico precoce, tratamento oportuno e demais medidas de prevenção e controle, incluindo o uso correto de preservativos. Ainda, trabalham-se a minimização do estigma, consequentemente do preconceito e a responsabilidade consigo e com o parceiro.

Após as atividades, faz-se uma discussão sobre o tema e as dúvidas são esclarecidas. Para finalizar as palestras e oficinas, aplica-se um questionário para os indivíduos que concordam em avaliar o projeto e verificar o aprendizado. Este questionário é composto por questões simples sobre o tema e de avaliação da relevância, conteúdo, material didático e metodologia trabalhados. Além disso, no final do instrumento de avaliação, há um espaço reservado para sugestões dos participantes em relação ao projeto e temas relacionados que poderiam ser incluídos em novas apresentações.

Nas Campanhas educativas, foi ofertado para a população a possibilidade de realizar a sorologia rápida para Hepatite C. O kit empregado para o teste foi Teste Rápido OL HCV. Os testes positivos foram encaminhados ao Centro de Testagem e Aconselhamento (CTA) para teste confirmatório, tratamento e aconselhamento. $\mathrm{Na}$ oportunidade, também foi informado a população que o CTA faz o referido teste, além das sorologias para Hepatite B, HIV e Sífilis.

Trata-se de um estudo quantitativo, buscando a multiplicação da informação sobre as DST/AIDS, Hepatites Virais e sexualidade, formas de contágio, sorologia por meio de testes rápidos e convencionais, tratamento e outros assuntos relacionados ao tema.

Para o público em geral, são organizados stands temáticos, para multiplicação do conhecimento e troca de 
informações e saberes entre a equipe do Projeto e o público participante.

\section{RESULTADOS E DISCUSSÃO}

\subsection{DADOS OBTIDOS}

Ao todo, nos últimos três anos o projeto alcançou um público de 139.160 pessoas.

Em 2013 o projeto trabalhou com 1.250 pessoas e 11.000 visualizações no BLOG. Já em 2014, o público alcançado diretamente foi de 1.310 pessoas, e verificouse 27.769 visualizações no BLOG. Foi criada a página própria 'Doenças Sexualmente Transmissíveis e Hepatites Virais' no Facebook, com 505 curtidas até o momento.

No ano de 2015 o público alcançado diretamente foi de 1.822 pessoas, e verificouse 94.656 visualizações no BLOG, recebendo anonimamente dúvidas que foram sanadas. Criou-se também o perfil no Facebook 'Saúde DST' que possui 848 amigos, com informativos diários.

Assim, o projeto alcançou nesses períodos, 139.160pessoas direta e indiretamente, sendo que o público atingido diretamente nos anos de 2013, 2014 e 2015 foi de 4.382 pessoas e composto dos seguintes segmentos: alunos do ensino fundamental e médio (Escola Estadual Samuel Engel, Escola Estadual Levindo Lambert, Escola Estadual Judith Viana), cursinho pré-vestibular da
UNIFAL-MG; crianças matriculadas no CVT (Centro Vocacional Tecnológico); acadêmicos da Universidade Federal de Alfenas - UNIFAL; indivíduos da terceira idade que frequentam as atividades da UNATI (Universidade Aberta a Terceira Idade);jovens, adultos e idosos nos Centro de Referência de Assistência Social de Alfenas (CRAS); crianças que frequentam a Associação Beneficiente CARITAS; comunidade participante das campanhas (Dia Internacional da Mulher, Dia pelo Uso Racional de Medicamentos, Dia dos Namorados, Dia Nacional do Idoso, Dia do Servidor Público e Dia Mundial de Luta Contra a AIDS). Ainda, teve-se o público indireto, alcançado de forma virtual pelo blog (http://dstaidsunifal.blogspot.com.br/), perfil e a página do facebook, somando ao todo, 134.778 pessoas.

Gráfico 1 - Levantamento do público atingido nos anos de 2013, 2014 e 2015.

\section{Público atingido nos anos de 2013-2015}

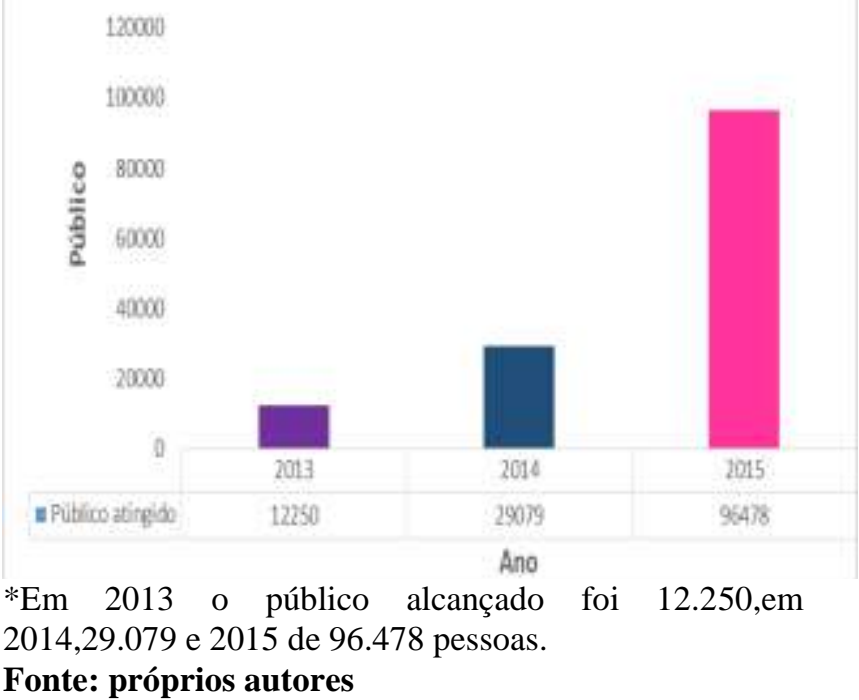


Considerando o questionário preenchido pelos indivíduos que concordam em avaliar o projeto e verificar o aprendizado, constatou que nas escolas do ensino médio, a média de acertos foi de 6,9 pontos, em um total de 10.

As turmas avaliadas da Escola A foram o $1^{\circ}, 2^{\circ}$ e o $3^{\circ}$ ano do ensino médio.

No primeiro ano, a média geral de acertos foi de 6,7, sendo que 63 alunos participaram do preenchimento do questionário. Do total, 33 alunos $(52,38 \%)$ eram do sexo masculino e $30(47,61 \%)$ eram do sexo feminino, com médias de acerto de 6,76 e 7,06 respectivamente.

No segundo ano, a média geral de acertos foi de 7,0 pontos, sendo que 108 alunos responderam ao questionário. Do total, 56 alunos $(51,85 \%)$ eram do sexo feminino e $52(48,14 \%)$ eram do sexo masculino. A média de acertos do sexo feminino foi de 7,21 , enquanto a média de acertos do sexo masculino foi de 6,85 .

Já no terceiro ano dessa mesma escola, a média geral de acertos foi de 7,41 pontos, sendo que 81 alunos responderam ao questionário. Do total, 49 alunos $(60,49 \%)$ eram do sexo feminino e $32(39,50 \%)$ eram do sexo masculino. A média de acertos do sexo feminino foi de 7,78 enquanto a média de acertos do sexo masculino foi de 6,84.

Gráfico 2 - Média de acertos para questões relacionadas a DST/AIDS e Hepatites Virais respondidas por alunos do ensino médio da Escola $\mathrm{A}$.

\section{Média de acertos}

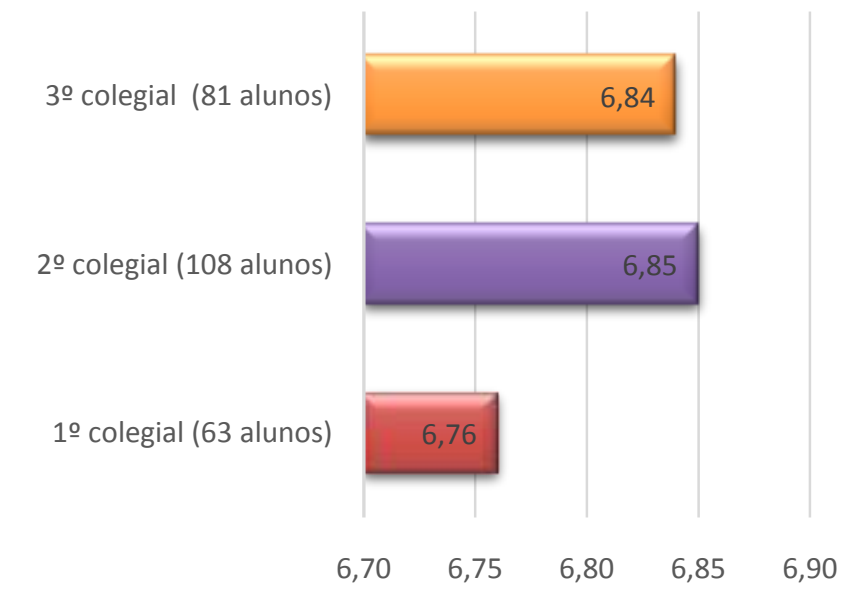

Fonte: próprios autores

Gráfico 3 - Média de acertos do sexo feminino e masculino para questões relacionadas a DST/AIDS e Hepatites Virais respondidas por alunos do ensino médio da Escola A.

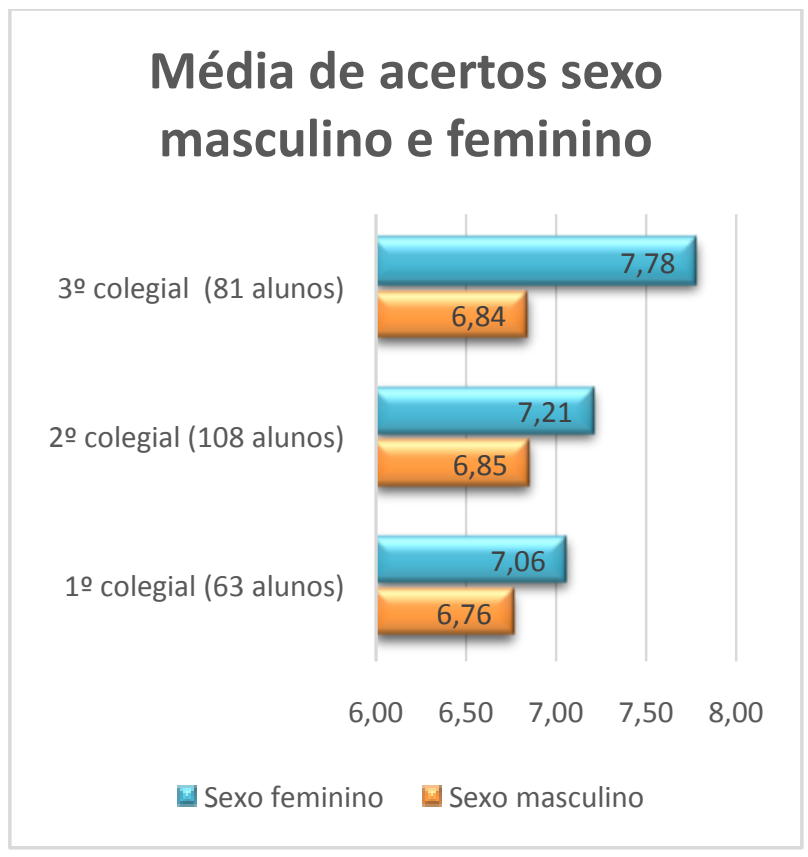

Fonte: próprios autores 
As turmas avaliadas da Escola B foram, o $9^{\circ}$ ano do ensino fundamental e o $3^{\circ}$ ano do ensino médio.

$\mathrm{Na}$ turma do nono ano, a média geral de acertos foi de 5,8 pontos, sendo que 14 alunos responderam ao questionário. Do total, 10 alunos $(71,4 \%)$ eram do sexo feminino e 4 $(28,6 \%)$ do sexo masculino. A média de acertos do sexo feminino foi de 6,0 enquanto a média de acertos do sexo masculino foi de 5,2. Já no terceiro ano do ensino médio, a média geral de acertos foi de 7,2 pontos, sendo que 26 alunos responderam ao questionário. Do total, 20 alunos (76,9\%) eram do sexo feminino e $6(23,1 \%)$ eram do sexo masculino. A média de acertos do sexo feminino foi de 7,0, enquanto a média de acertos do sexo masculino foi de 7,7; sendo observado, que os alunos do sexo masculino se mostraram muito interessados no assunto, participando bastante, interagindo e dando sugestões de temas a serem abordados.

Os principais erros apresentados pelos alunos foram ao que se refere à transmissão das hepatites virais (principalmente entre B e C), além disso, vários deles apontaram o agente transmissor da AIDS como sendo bactéria e ainda, observou-se certa confusão para distinguir doenças que causam feridas das doenças que causam corrimento.

As sugestões acerca de outros assuntos a serem abordados em atividades educativas futuras foram diversas, dentre elas: uso de drogas, câncer de mama e de próstata, saúde bucal, aborto, gravidez na adolescência, cura das doenças, preconceito e início da vida sexual.

Na campanha do Dia Nacional de Luta contra a AIDS (1 de dezembro de 2014), realizada na Universidade Federal de Alfenas, foram aplicados questionários para a avaliação do conhecimento sobre DST/AIDS e Hepatites Virais, sendo que 101 acadêmicos concordaram em participar da pesquisa. Os questionários foram corrigidos com pontuação de 0 a 10 . Na Universidade, a média foi de 6,7 .

Esses dados evidenciam que quando o assunto é Doenças Sexualmente Transmissíveis, as dúvidas estão presentes em vários níveis de escolaridade. A maior incidência de erros, independente da escolaridade, concentrou-se nas questões sobre hepatites virais, havendo certa confusão quanto aos tipos, como são adquiridas e tratadas.

Nas Escolas Estaduais, os erros em relação a AIDS, tiveram destaque, uma vez que muitos jovens acreditam que a doença é causada por uma bactéria, ao invés do vírus, além da não relação da doença com drogas injetáveis, transmissão congênita e amamentação.

As dúvidas mais frequentes desse levantamento foram sobre o tratamento das DST, relacionando também com o acesso aos medicamentos. Ainda, quanto tempo um portador leva para descobrir que possui uma 
Doença Sexualmente Transmissível e como é sua vida, a partir do momento da descoberta.

As palestras realizadas foram muito bem recebidas pelo público, designadas como muito informativas, com imagens que chamaram atenção, ressaltando a importância da prevenção, conscientização e multiplicação do conhecimento adquirido.

\subsection{ATIVIDADES DESENVOLVIDAS}

Foi criado o BLOG sobre o tema (www.dstaidsunifal.blogspot.com.br), a fim de alcançar indiretamente um público maior (jovens, adultos e idosos que tem acesso à internet). O blog encontra-se disponível para acesso, desde novembro de 2012, tendo do início de sua criação até dezembro de 2015,120.474visualizações, atingindo também o público de outros países, como Portugal, Estados Unidos, Rússia, Índia, Quênia, Moçambique, Angola, entre outros.

Houve desdobramentos com o desenvolvimento de novas atividades, trabalhando com os jovens do ensino fundamental e médio sobre o uso de drogas e suas consequências, com a terceira idade do CRAS e da UNATI desenvolveu-se temas de saúde do homem e da mulher, como o câncer de próstata, de mama e colo do útero.

Este projeto de extensão realiza algumas atividades de ensino como o treinamento dos participantes; reuniões semanais para estudo e atualizações sobre os temas abordados, programação e apresentação de sugestões; oficinas e palestras educativas sobre DST/AIDS e Hepatites Virais; barracas temáticas, stands educativos e folders educativos do projeto.

\subsubsection{Atividades Educativas}

- Escola Estadual Samuel Engel, Judith Viana e no cursinho pré-vestibular UNIFAL-MG foram ministradas palestras educativas, totalizando 19 turmas, em um total de342, 275 e 184 alunos, respectivamente, totalizando um número de801 ouvintes.

- Na Escola Estadual Levindo Lambert trabalhou-se com jovens do oitavo e nono ano, totalizando 170 alunos, abordandoos de maneira dinâmica e interativa.

- Trabalhou-se de maneira dinâmica, por meio de vídeos sobre sexualidade, jogos interativos sobre as Doenças Sexualmente Transmissíveis, além de explicações de fácil entendimento, para 45 crianças de 9 a 14 anos, no Centro Vocacional Tecnológico e no CRAS de Alfenas.

- Realizou-se um curso para as manicures de Alfenas, ministrado em parceria com o PET- Farmácia, com abordagem das Doenças sexualmente transmissíveis, junto de seus diagnósticos e modos de prevenção, além de todo o cuidado que se deve ter dentro do salão de beleza, totalizando 8 manicures. 
- O grupo ministrou a palestra 'Doenças Sexualmente Transmissíveis e Hepatites Virais na Semana de Prevenção de Acidentes Perfuro cortantes' realizada para 45 funcionários do Supermercado UNISSUL de Alfenas.

- Em parceria com o Programa de Educação Tutorial dos cursos de Farmácia e Enfermagem (PET Farmácia e PET - Enfermagem, o projeto participou de dois ciclos de seminários, aberto para todos os universitários da Faculdade Federal de Alfenas, totalizando 80 acadêmicos.

- Parceria com a UNATI - UNIFAL-MG, desenvolvendo atividade educativa voltada para a terceira idade, 48 idosos, desenvolvendo uma abordagem mais dinâmica e aprofundando nas Doenças Sexualmente Transmissíveis que tem maior incidência nos idosos. Alguns trechos de notícias para reflexão foram discutidos dinamicamente, como um que fazia a comparação das mulheres da terceira idade, com as cinderelas do mundo moderno, já que muitas mulheres vão descobrir ser soropositivas na viuvez, adquirindo a doença dentro de sua própria casa. A palestra foi muito bem recebida, apesar do grupo de pessoas que estavam presentes ter sido pequeno, já que muitas idosas alegaram não ter mais marido ou que não se interessam por esse assunto. Trabalhou-se também com saúde do homem e da mulher de uma forma muito interativa, conscientização sobre os exames de prevenção do câncer de próstata e do auto exame das mamas.

O projeto foi convidado para realizar novas atividades, partindo do pedido das próprias senhoras, que avaliaram a atividade como muito proveitosa e importante para todos.

- O projeto Doenças Sexualmente Transmissíveis e Hepatites Virais participou da Semana Nacional de Ciência e Tecnologia (SNCT), realizada na cidade de Poços de Caldas, Minas Gerais, no shopping local, em 2014. Foi aberta para toda a comunidade, tendo o stand informativo com grande variedade de material educativo a ser distribuído, junto de preservativo, lubrificantes, estando aberto para sanar possíveis dúvidas e fornecer as informações necessárias. Atingiu um público de 60 pessoas, desde jovens e adultos.

- Em 2015 a SNCT foi realizada na Universidade Federal de Alfenas, com stand educativo, aberta para a comunidade externa e acadêmica, totalizando 181 visitantes.

- Ainda, na SNCT os integrantes apresentaram um mini curso sobre 'Atualização na prevenção e Controle de Doenças sexualmente Transmissíveis'.

- Palestra educativa na Associação Beneficente CARITAS de Alfenas, 
trabalhando sobre sexualidade, gravidez na adolescência, educação sexual e DST, com 16 crianças, na faixa etária de 10 a 15 anos.

- O projeto foi apresentado no Seminário Interno para a Apresentação dos Projetos de Extensão Realizados em 2013, 2014 e 2015, evento realizado na UNIFAL-MG de abrangência local, para uma banca avaliadora, a qual teceu muitos elogios à equipe do projeto.

\subsubsection{Campanhas educativas}

- Campanha no dia da Acolhida ao Calouro da UNIFAL-MG, com stand educativo e orientações ao público (200 pessoas).

- Campanha do Dia Internacional da mulher, realizada no dia 8 de março, com stand educativo e distribuição de material educativo, juntamente com preservativos, realizada na Praça Getúlio Vargas, atingindo um público de 60 pessoas.

- Campanha pelo Uso Racional de Medicamentos em 2013, 2014 e 2015, com stand educativo, distribuição de material educativo, preservativos, com um público de aproximadamente 380 pessoas.

- Campanha em comemoração ao Dia dos Namorados em 2013, 2014 e 2015, com os alunos da UNIFAL-MG, com distribuição de material educativo, juntamente com preservativos, para 828acadêmicos.

- Campanha em comemoração à Semana Nacional do Idoso, com a terceira idade da UNATI, com realização de stand educativo, aconselhamento, sanando dúvidas, além da palestra motivacional (50 maneiras de ser feliz depois dos 50), totalizando 50 idosos.

- Campanha do Dia do Servidor Público, realizada na Universidade Federal de Alfenas, com realização dos testes rápidos para Hepatite $\mathrm{C}$, orientação $\mathrm{e}$ demonstração do uso correto dos preservativos feminino e masculino, tendo a participação de 300 pessoas. Foi realizada intensa distribuição de material educativo, preservativos e divulgação da informação. Nessa oportunidade, foram realizados de 150 testes rápidos para Hepatite C (Teste Rápido OL HCV), sendo que148 testes deram não reagentes e 2 reagentes. Esses dois pacientes foram encaminhados ao Centro de Testagem e Aconselhamento (CTA) para teste confirmativo e acompanhamento médico e psicossocial.

- A equipe participou do I Encontro de Qualidade de Vida e Promoção à Saúde dos Servidores do Campus da UNIFAL em Varginha, com 40 servidores públicos e acadêmicos participando.

- Campanha Mundial de Luta contra a AIDS, no dia primeiro de dezembro, 
voltada para toda a população, com montagem do stand educativo, distribuição de materiais educativos, preservativos femininos e masculinos, além do esclarecimento de dúvidas e a conscientização da importância do diagnóstico precoce, por meio de testes rápidos, com um público aproximado de 639 pessoas.Essa campanha foi realizada na UNIFAL-MG, no Centro de Vivencias de Alfenas e no Posto de Saúde Vila Formosa.

Em todas as atividades realizadas, houve a divulgação do blog, do CTA e a importância da prevenção, diagnóstico precoce e tratamento oportuno.

Deve-se ressaltar que a comunidade externa participou da concepção do projeto de extensão, teve participação ativa no desenvolvimento do projeto, além disso, avaliou as atividades realizadas.

Quanto ao impacto social, o tema do projeto é instigante, pois aborda assuntos pouco discutidos pela família e pela escola. $\mathrm{O}$ anseio por informações corretas é detectado nas palestras, oficinas, eventos e demais atividades do projeto.

\section{As Doenças Sexualmente}

Transmissíveis são problemas enfrentados pela população e sua prevenção e controle desafiam os órgãos de educação e saúde. Através das oficinas, palestras, eventos e do blog do projeto estabeleceu-se um contato entre os acadêmicos da equipe executora e a sociedade em geral, com troca de experiências e esclarecimentos de dúvidas.

O Departamento de DST/AIDS/HIV do Ministério da Saúde realiza ações de comunicação em saúde para a prevenção e controle dessas doenças: campanhas de massa, veiculadas no Dia Mundial de Luta contra a AIDS ( $1^{\circ}$ de dezembro) e durante o carnaval, bem como os materiais educativos e informativo, que tem o importante papel de disseminar informações sobre o tema, colaborando também para o enfrentamento do preconceito e do estigma contra as pessoas vivendo com HIV e segmentos mais vulneráveis da população.

Ressalta-se que, o projeto ora apresentado, também realizou essas mesmas campanhas, além das outras já citadas, em lugares públicos, na universidade, tendo contato direto com a população e também via internet, por meio dos trabalhos desenvolvidos no blog e na página do Facebook.

Fundamentando-se nos levantamentos estatísticos, por meio de pesquisas realizadas pelo Ministério da Saúde, sabe-se que a grande maioria da população brasileira entre 15 e 64 anos $(96,6 \%)$ concorda com a afirmação de que o uso de preservativos é a melhor maneira de evitar a infecção pelo HIV e $95,7 \%$ concordam que uma pessoa pode ser infectada nas relações sexuais sem preservativo. Aproximadamente $96 \%$ dos 
indivíduos concordam que não podem ser infectados por picada de inseto, 92\% concordam que uma pessoa com aparência saudável pode estar infectada pelo HIV e 91,2\% dos indivíduos sabiam que podem ser infectados pelo HIV ao compartilhar seringas. Por outro lado, nota-se que, cerca de um quinto da população ainda acredita que uma pessoa pode ser infectada pelo HIV ao compartilhar talheres (7\%) ou ao usar banheiros públicos (21,4\%). Quando o assunto é a forma de transmissão do vírus, os índices de erros são os maiores, pois ainda existem muitas dúvidas sobre as formas que se podem contrair o HIV (BRASIL,2011).

Os custos do manejo das DST e suas complicações são substanciais. Elas aparecem entre as 10 principais causas de procura por serviços de saúde na maioria dos países em desenvolvimento e respondem por $17 \%$ das perdas econômicas com o binômio saúde/doença (MAYAUD; MABEY, 2004).

A sexualidade é um assunto ainda pouco abordado no âmbito familiar, principalmente na classe média baixa. A intervenção educativa em escolas públicas contribui para a multiplicação do conhecimento sobre formas de transmissão, sintomas e complicações que as DTS podem ocasionar, o que torna um caminho para o conhecimento, reflexão e vivência saudável da sexualidade (BRASIL, 2006).

A partir dessas informações é importante que a educação em saúde seja difundida entre a população, disseminando, cada vez mais, as maneiras de prevenção e controle dessas doenças. E para isso, é essencial a continuidade dos trabalhos desenvolvidos tanto pelo Ministério da Saúde, quanto os desenvolvidos pelas instituições de educação e saúde.

O Departamento de DST/AIDS/HIV, em parceria com outras áreas do Ministério da Saúde, elabora e disponibiliza protocolos e materiais técnicos voltados para profissionais de saúde, bem como campanhas dirigidas para a população geral, com o objetivo do controle das DST no país e da melhoria da qualidade de vida de sua população.

Outras universidades desenvolvem ações educativas acerca deste assunto, como por exemplo, os projetos "DST/AIDS na mira da prevenção" da Universidade Federal de Juiz de Fora, "DST/AIDS" da Universidade Estadual do Norte Fluminense, "Universidaids na Prevenção de DST/AIDS Junto à População Indígena" da Faculdade de Medicina da Universidade Federal de Alagoas e também existe um Pólo de Prevenção DST/AIDS, criado pela Universidade de Brasília no Facebook.

\section{CONCLUSÃO}

Portanto, espera-se que, por meio de todas essas atividades relatadas e dados apresentados, mais universidades no país, também criem projetos que objetivem a 
multiplicação do conhecimento em DST/Aids

e Hepatites virais para a população em geral,

a fim de transformar positivamente o cenário que se encontram essas doenças na saúde brasileira. Este projeto de extensão contribuiu para a formação técnico, científica, ética,

\section{REFERÊNCIAS:}

BELÉM.Prefeitura Municipal de Belém Departamento de ações e saúde. Doenças sexualmente transmissíveis em gestantes. Belém, 1999.

BRASIL. Ministério da saúde. Boletim Epidemiológico - Aids e DST. Ano VIII, n.1.Dados referentes ao período jul/2013a jun/2014. Brasília: Ministério da Saúde. Disponível em: 〈www.aids.gov.br〉.

BRASIL. Ministério da Saúde. Secretaria de Vigilância em Saúde. Guia de vigilância epidemiológica. Ministério da Saúde, Secretaria de Vigilância em Saúde. - 6 ed. - Brasília : Ministério da Saúde, 2005. 816 p.

<www.bvsms.saude.gov.br>

BRASIL. Ministério da Saúde. Hepatites virais; o Brasil está atento. Brasília : Ministério da Saúde, 2005.

BRASIL. Ministério da Saúde. Manual de Controle da Doenças Sexualmente Transmissíveis - DST. $4^{\mathrm{a} e d}$. Brasília: Ministério da Saúde, 2006.

BRASIL. Ministério da Saúde. O SUS de A a Z; garantindo saúde nos municípios. 3 ed. - Brasília : Editora do Ministério da Saúde, 2009.

BRASIL. Ministério da Saúde. Pesquisa de conhecimentos, atitudes e práticas na população brasileira. Brasília - Distrito Federal, 2011. Disponível em: <http://bvsms.saude.gov.br/bvs/publicacoes/pesq cidadã e humanística de toda equipe participante.

Ainda, contribuiu para a formação de futuros profissionais de saúde comprometidos com as necessárias transformações sócio, cultural e sanitárias do país.

uisa_conhecimentos_atitudes_praticas_populaca o_brasileira.pdf $>$.

BRASÍLIA. Ministério da Saúde. Secretaria de Vigilância em Saúde. Programa Nacional de DST e AIDS. Prevalências e freqüências relativas de Doenças Sexualmente Transmissíveis (DST) em populações selecionadas de seis capitais brasileiras, 2008.

DST, Aids e Hepatites Virais .Boletim Epidemiológico - Hepatites Virais. Ano II, $\mathrm{n}^{\mathrm{o}}$ 01. Brasília: Ministério da Saúde, 2011b. Disponível em: 〈www.aids.gov.br>

GIL, A. C.; TEMPORINI, E. R. Prevenção da aids entre estudantes universitários: existe influência dos pares? Medicina, Ribeirão Preto, v.33, Abr.-Jun., p.147-154. 2000.

HOYOS, R. C.; SIERRA, A. V. El estrato socioeconómico como factor predictor del uso constante del condón en adolescentes. Rev Saúde Pública, v.35, n.6, p.531-538. 2001.

MAYAUD P.; MABEY D. Approaches to the control of sexually transmitted diseases. In: Sexually Transmitted Infections. 80 (3):174182, Jun, 2004.

PEREIRA G.S.; BORGES C.I. Conhecimento sobre HIV/ AIDS de participantes de um grupo de idosos, em Anápolis-Goiás. Esc Anna Nery. 2010;14(4):720-5.

RUDELIC-FERNANDEZ D. A Sexualidade dos Jovens em Tempos de AIDS: Atos e Falas. In: Borillo D, Fédida P, Fraisse G, Gayon J, Matlock J, Rudelic-Fernandez (eds) A 
Sexualidade tem futuro? Edições Loyola, São Paulo, p. 55-72, 200

SANTOS, N. J. S.; BARBOSA, R. M.; PINHO, A. A.; VILLELA, W. V.; AIDAR, T.; FILIPE, E. M. V. Contextos de vulnerabilidade para o HIV entre mulheres brasileiras. Cadernos de Saúde Pública. vol.25, supl. 2 , Rio de Janeiro, 2009

SENADO FEDERAL. Hepatite pode ser evitada; os tipos $\mathbf{B}$ e $\mathbf{C}$ da doença podem se tornar crônicos e levar à cirrose e ao câncer. Acesso em 10 de março de 2016. Disponível em:

\section{Agradecimento aos parceiros}

- CTA -Centro de Testagem e Aconselhamento de Alfenas (Instituição governamental municipal) <http://www.senado.gov.br/noticias/jornal/cidad ania/hepatite/not001.htm>

TAKIUTI, A. D. Quase metade dos jovens homossexuais não usa camisinha. Acesso em 12 de março de 2016. Disponível em: <http://drauziovarella.com.br/sexualidade/quasemetade-dos-jovens-homossexuais-nao-usapreservativos/>.

TEIXEIRA R.; MARTINS FILHO O.A.; OLIVEIRA G.C. Hepatite C: aspectos críticos de uma epidemia silenciosa. Belo Horizonte: COOPMED/Rio- Editora Fiocruz; 2005. 212 pp.

- CAFAR - Centro Acadêmico da Farmácia (Organização estudantil)

- NAFAU -Núcleo de Atenção farmacêutica da Farmácia Universitário(Projeto de Extensão)

- PET Farmácia da UNIFAL-MG (Programa de Educação Tutorial do MEC/SESU) 